\title{
La democracia humillada. El orden político en tiempos de apaciguamiento
}

\section{Pedro Rivas Nieto'}

Resumen: La democracia liberal -como sistema y como "estado de las cosas"- y el orden internacional después de 2001 pasan por una crisis de alcance mundial. El autor afirma que la ruptura con los logros de la democracia liberal, si sólo se halla integridad en ideas o regímenes políticos "puros" y no se tiene en cuenta los bienes imperfectos, es un error que podemos pagar muy caro. ¿ंTenemos claro hacia dónde va el mundo? En primer lugar se presenta un recorrido de lo sucedido desde la caída del Muro de Berlín hasta el 11 de septiembre de 2001 y a continuación se analiza la reacción tras estos hechos, tanto en los Estados Unidos de América como en la Unión Europea. En la parte más reflexiva y propositiva, el autor hace una crítica de los "paradigmas de la equidistancia" y de la llamada "política del apaciguamiento". En la conclusión, reacciona vigorosamente contra quienes critican irreflexivamente la democracia liberal. La desaparición o deterioro de ésta conllevaría la pérdida de la libertad y de la posibilidad de la justicia.

Palabras clave: democracia liberal, libertad, pacifismo, paradigmas de la equidistancia, política de apaciguamiento.

Fecha de recepción: 28 de febrero de 2014.

The humiliated democracy. The political order in times of appeasement

Abstract: Liberal democracy -as a system and as a "state of things"- and the interna-
La démocratie humilié. L'ordre politique en temps d'apaisement

Résumé: La démocratie libérale-comme un système et comme «état des choses»- ef

' Universidad Loyola Andalucía. 
tional order after 2001 go through a global crisis. The author claims that the break with the achievements of liberal democracy, if only there is integrity in ideas or "pure" political regimes and does not take into account the imperfect goods, is an error that we can pay dearly. We have clear where the world is going? First presents a tour of what has happened since the fall of the Berlin wall until the September 11, 2001 and then is analyzed the reaction after these events, both in the United States of America and the European Union. In its most thoughtful and purposeful, the author makes a critique of the "paradigms of equidistance" and of the so-called "policy of appeasement". In conclusion, he reacts vigorously against those who rashly criticize liberal democracy. The disappearance or deterioration of this would result in the loss of freedom and the possibility of Justice.

Key words: liberal democracy, freedom, pacifism, paradigms of equidistance, policy of appeasement. l'ordre international après 2001 traversent une crise mondiale. L'auteur affirme que la rupture avec les acquis de la démocratie libérale, si seulement il y a intégrité dans les idées ou les régimes politiques "purs» et $n$ 'est pas pris en compte les biens imparfaits, elle serait une erreur que l'on pourrait payer très cher. Avons-nous une idée claire d'où va le monde? L'auteur tout d'abord présente un tour de ce qui s'est passé depuis la chute du mur de Berlin et jusqu'au 11 septembre 2001 , puis la réaction est analysée après ces événements, tant dans les États-Unis comme dans I'Union européenne. Dans la partie réfléchie et délibérée du texte, I'auteur faitune critique des paradigmes «d'équidistance» et de la politique dite «d'apaisement». En conclusion, il réagit vigoureusement contre ceux qui critiquent inconsidérément la démocratie libérale. La disparition ou la dégradation de celle-ci se traduirait par la perte de la liberté et de la possibilité de la justice.

Mots clé: démocratie libérale, liberté, pacifisme, paradigmes d'équidistance, politique d'apaisement.

\section{Introducción}

Hoy hablaré en este foro de algo que, a mi juicio, debería preocuparnos hondamente porque dificulta la estabilidad de nuestros regímenes políticos. Daña a la democracia -entendida como sistema y como "estado de las cosas", por emplear la conocida idea de Alexis de Tocqueville- y lastima al orden internacional. Esta tarde hablaré del estado del mundo tras la caída del Muro de Berlín, de las alteraciones en los Estados Unidos y en Europa después del 11-S, del surgimiento de los "paradigmas de la equidistancia" y de los ataques acerbos a los fundamentos de la democracia en tierras democráticas. Es_decir, de asuntos que ponen al mundo en aprietos y facilitan que la democracia y las democracias entren en crisis, incluso a escala mundial. 
Quizá mi discurso -les prevengo por sentido del honor-, suene algo conservador -y es probable que esto contraríe, al menos, a la mitad del auditorio-; pero si lo hago, a sabiendas de que me perjudica, es porque creo firmemente que hay que conservar no pocos factores de la democracia liberal que han permitido abundantes logros de la contemporaneidad. No empleo el concepto conservador en el sentido en el que Magris lo hacía, cuando decía con belleza que "es conservador el diablo porque no cree en el futuro ni en la esperanza, porque no consigue siquiera imaginar que Adán pueda transformarse, que la Humanidad pueda regenerarse", reconociendo que el conservadurismo es la causa de males que, al aceptarlos como inevitables, los permite. Lo hago en otro sentido, afirmando que la ruptura con algunos logros claros de los hombres puede lastimarnos, si se incurre en el peligroso juego de hallar integridad solo en personas, ideas o regímenes políticos inmaculados; si no se tiene en cuenta que hay bienes imperfectos que no deben modificarse si queremos que sean de provecho. Ese puritanismo vicioso -permítaseme la expresión-, que solo encuentra virtud en lo que no se ha contaminado de vida, nos hace flaco favor. Porque a veces, lo que ha servido -como la democracia- hay que mantenerlo, pues puede seguir a nuestro servicio, al de todos los hombres. Acaso no hay que buscar nuevos caminos sino, como decía Marcel Proust, tener nuevos ojos.

Si este es, resumidamente, el estado de las cosas del que partiré, y si ya les he confesado mis convicciones, intentaré explicar, siquiera sea por encima, qué está pasando en la actualidad y por qué creo que nos afecta a todos. Vayamos, entonces, por partes: ¿Cómo se ha modificado el orden internacional en los años recientes? ¿Seguimos bebiendo de las mismas fuentes que en los tiempos de la guerra fría? ¿Acaso no tenemos claro hacia dónde va el mundo?

\section{Desde la caída del Muro de Berlín hasta el I I de septiembre de 200 I}

Cuando cayó el Muro de Berlín hace poco más de veinte años acabó el siglo más corto de la Historia humana, tal y como afirmó Hobsbawn. Acabó el siglo que duró setenta años, desde el triunfo de la revolución bolchevique hasta el fin del imperio soviético. Y en aquel momento las relaciones internacionales comenzaron a buscar nuevas bases para su desarrollo. Decía el historiador estadounidense y premio Pulitzer Arthur Schlesinger que el mundo de la guerra fría era de una "elegante sencillez". Cualquiera sabía a qué atenerse. Sabía qué le tocaba dependiendo de en qué parte del mundo hubiera nacido; tras la caída del Muro de Berlín y la 
desaparición de la Unión Soviética no se sabía. El mundo anterior tenía un orden; el mundo posterior, no. Antes se podía decir, deformando -con poca prudenciauna conocida frase del Che Guevara, "contra el comunismo siempre". Y después, ¿qué? ¿Contra quién, siempre -suponiendo que en el complejo panorama de la política internacional sea esencial ir contra alguien-?

La verdad es que en los años noventa sólo se estaba seguro de que el mundo tenía desafíos. Y los desafíos de entonces -media docena-, que a buena parte de los estudiosos de las relaciones internacionales y a los ciudadanos normales les sonaban apocalípticos, después se convirtieron en una triste realidad. No se sabía qué iba a pasar con el polvorín postsoviético, ni con la China comunista -que aplicaba el capitalismo sin miramientos en algunas zonas de la república-, ni con las tensiones del arco islámico del norte de África y del Cáucaso-que entonces, se decía, iban a convertirse en zonas en donde se podía incubar el virus del terrorismo-; y junto a estos tres problemas, no se sabía qué podría ocurrir con la explosión demográfica del sur y con la creciente emigración posterior, con las armas de destrucción masiva y con el terrorismo internacional -que empezaba a preocupar no sólo a los ministerios del interior, sino a los de defensa, de los Estados consolidados del Occidente-

Los tres últimos desafíos -emigración desbordada, armas de destrucción masiva y terrorismo a gran escala-, que entonces sonaban exagerados, se convirtieron en un plazo breve en una peligrosa y patética realidad que modificó la política de los Estados importantes. La duda era, por tanto, saber qué tipo de mundo se tenía entonces y a qué amenazas se enfrentaban los ciudadanos del "mundo libre". ¿Avanzábamos hacia la unificación, o perseverábamos en la fragmentación? ¿Nos uníamos más, tal y como sugerían ciertas proclamas y la, a veces, exitosa Unión Europea, o caminábamos hacia el cisma definitivo, tal y como deseaban los abundantes nacionalismos rejuvenecidos? ${ }_{2}$ El universalismo moral moderno contenido en los principios democráticos iba a acabar por imponerse por sí mismo, o la identidad específica de todos y cada uno de los pueblos iba a marcar el paso de la nueva era? ¿ílbamos a regirnos por normas sólidas que refrenasen las tropelías o permaneceríamos en estado hobbessiano, en permanente e inquietante lógica prebélica de guerra de todos contra todos? Lo único que se sabía de verdad era que se había acabado el antiguo mundo comunista y que pervivía el mundo capitalista, con sus bondades y maldades. Era aquél un momento de continuidad y cambio. Había surgido un ordo novo, un nuevo orden, y sólo hacía falta saber cuál era. Como decía Kissinger a quien quisiera escucharlo -y no suele ser bueno citarlo, dada su mala prensa, ganada a pulso-, solo se habían oído los dolores de parto. 


\section{Los Estados Unidos después del I I de septiembre de 200 I}

En esas andaba el mundo cuando, un 11 de septiembre de 2001, un atentado terrorista sin precedentes golpeó el corazón de los Estados Unidos. Por vez primera el territorio del país más poderoso del mundo había sido atacado, no en una operación militar, sino en una agresión espectacular llevada a cabo por un puñado de delincuentes -políticos, es cierto, pero delincuentes-. El terrorismo, del que ya podía decirse que buena parte era mundial porque su escenario era el mundo entero, iba a cambiar el aún indefinido panorama internacional. Un nuevo enemigo huidizo como pocos se colaba entre los convencidos demócratas del Occidente.

El terrorismo universal -o global, en calco directo del inglés-mostró que el mundo era menos seguro y los Estados Unidos, que eran por aquel entonces la potencia fundamental sin paralelo posible, mostraron al mundo que eran vulnerables. Si el concepto fundamental que se manejaba en los círculos académicos y políticos en los años setenta del siglo XX era "desarrollo" y en los años noventa era "globalización", en ese momento era "seguridad". El mundo entero y la gran potencia mundial tenían nuevos enemigos y muchas naciones rechazaban la hegemonía de los Estados Unidos en el período posterior al 11 de septiembre de 2001.

Tras el 11 de septiembre de 2001 las tendencias de los años noventa cambiaron con la denominada Doctrina Bush, la denominación periodística de la llamada Estrategia de Seguridad Nacional, construida poco después de aquella fatídica fecha. Se abandonaron tanto el Nuevo Orden Internacional de George Bush padre -que se asemejaba al surgido inmediatamente después de la Primera Guerra Mundial por su confianza en las instituciones internacionales y por el potente nacionalismo que propiciaba el surgimiento de nuevos Estados- como el intervencionismo humanitario y selectivo -no se olvide esto último- de Bill Clinton, y comenzó una nueva guerra contra un enemigo fuerte -el terrorismo- que había crecido junto con los cambios de la globalización.

Bush, el 6 de noviembre de 2001, dijo que ninguna nación debía dudar de que los Estados Unidos iban a perseguir y derrotar a los grupos terroristas de alcance mundial. Los actos del 11 de septiembre de 2001 -insistía- habían sido actos de guerra contra los EE.UU., sus aliados y la sociedad civilizada, y el mundo debía luchar contra ese mal porque el enemigo-el terrorismo en todas sus formas-no tenía régimen, ni religión, ni ideología, ni cuerpo concreto. Era buena idea no intentar culpar de simpatía con el terrorismo a doctrinas políticas, sistemas de gobierno o fes; era muy mala idea definir al enemigo como el mal puro, sin rostro, como un 
demonio cósmico, es decir, como algo inexistente en el mundo de los hombres, porque sus consecuencias eran imprevisibles y muy preocupantes. George Bush recordaba la relación cada vez más estrecha que los grupos terroristas mantenían entre sí y aseguraba que la amenaza máxima para el mundo era Al Qaeda, un grupo de alcance universal. El problema fundamental de los grupos terroristas era que disponían de armas de destrucción masiva. Por tanto, la nueva estrategia contra el terrorismo pretendía reducir la gravedad de la amenaza y para ello se quería aumentar la vigilancia en el interior de los EE.UU. y llevar a cabo una acción vigorosa en el exterior. Se proyectaba acabar con el apoyo de los Estados al terrorismo, persuadir a los Estados reacios, obligar a aquellos que se negasen, eliminar los "paraísos" de los terroristas y se quería colaborar con la comunidad internacional para fortalecer a los Estados débiles y prevenir el refuerzo y la aparición del terrorismo. Por eso los Estados Unidos decían -en los documentos de la nueva Estrategia de Seguridad Nacional y en el discurso público- que era necesario apoyar a los regímenes moderados, sobre todo en el mundo musulmán, que eran los destinatarios primeros del nuevo azote terrorista.

En este nuevo mundo, a priori más peligroso que el anterior, nació la intención de adaptar el derecho internacional a los nuevos tiempos, y esto ya suponía cierta modificación de lo conocido y de lo reconocido por todos durante más de medio siglo. Dicho de otro modo: en la Doctrina Bush no se renunciaba a la diplomacia -porque era necesaria y a ella se apelaba en la prevención- pero se robustecía el empleo de la fuerza. Aparecía la noción de legítima defensa ampliada porque se creía que era necesaria para garantizar la seguridad de los Estados y para modificar un derecho que servía de poco ante las nuevas amenazas. Las democracias podían cambiar, y debían hacerlo, o así se creía. Por ello Bush hablaba de la necesidad de extender la democracia por el mundo, de mantener buenas relaciones con las potencias y de derrotar a los terroristas y a los tiranos. De hecho, en la Doctrina Bush se decía que la etapa posterior al 11-S era la mejor oportunidad desde el nacimiento del estado-nación en el siglo $\mathrm{XVII}$ para construir un mundo en el que las potencias vivieran en paz, en vez de prepararse para la guerra.

Fuera como fuera la idea era clara: los EE.UU. querían estar preparados para actuar solos allá en donde sus intereses y responsabilidades lo requirieran. Frente a las nuevas amenazas la disuasión de la guerra fría ya no funcionaba. Hacían falta nuevas respuestas para las nuevas amenazas. Sin embargo, del viejo concepto disuasorio permanecía una idea muy clara: para mantener la paz era necesario un poder militar fuerte y la voluntad de hacer uso de él en caso de necesidad. 
Este era el orden internacional modificado tras la caída del Muro de Berlín y tras los atentados de septiembre de 2001. Ese era el mundo en que el terrorismo se había convertido en una nueva fuerza que amenazaba a los Estados, las naciones, las libertades, las haciendas y las vidas de los ciudadanos, y que iba a transformar la manera de enfrentarse a los problemas. Se ponía en peligro, tanto por el efecto del terrorismo como por las respuestas que los Estados le dieran, la calidad de la democracia y la estabilidad de las democracias. Podían entrar en crisis. Es más, dentro de Occidente parecía haber dos visiones, la europea y la estadounidense, y no parecían entenderse.

\section{La Unión Europea después del I I de septiembre de 200 I}

Los europeos hicieron lo que les tocaba. El efecto inmediato de la Doctrina Bush fue que la Unión Europea intentó ponerse de acuerdo para inventar una doctrina estratégica europea, muy difícil si se tenía en cuenta su naturaleza y su elevado número de miembros. Para la UE eran más importantes la globalización y el fin de la guerra fría que el $11-S$, tal y como mostraban la actividad nuclear de Corea del Norte o la proliferación de armamento en Oriente Próximo. Y en junio de 2003, Javier Solana, mister PESC, presentó un documento en el que se decía que era deber de Europa compartir la responsabilidad de la seguridad del mundo. Sin embargo, Europa creía que las amenazas más importantes no eran las que por tales tenían los Estados Unidos, sino las viejas, es decir, los conflictos regionales antiguos -como el árabe-israelí, o el de Cachemira-, el hambre, la corrupción, los riesgos medioambientales y la dependencia energética de Europa con respecto a otras zonas del mundo. Por supuesto que el terrorismo, las armas de destrucción masiva y los Estados rotos -en los cuales podía medrar el terrorismo y el crimen organizado- eran graves problemas, pero no mayores que los que ya habían dañado la convivencia.

Como respuesta a estas dificultades la Unión Europea proponía medidas sorprendentes: extender la estabilidad de la que ella misma disfrutaba a sus vecinos y al resto del mundo, proteger los derechos humanos, promover el libre comercio y el desarrollo y reforzar a la ONU tomando como base el derecho internacional, además de dotarla de instrumentos eficaces. Lo que esto significaba era que en la doctrina de seguridad que presentaba Solana se daba menos importancia a los medios militares que en los Estados Unidos, aunque se reconocía la necesidad de aumentar los recursos para la defensa, y no se hablaba de los ataques anticipatorios -o preventivos- aunque se mencionaba la necesidad de estar preparados 
para actuar antes de que se produjera una crisis. También se insistía en que había que reforzar los vínculos con los Estados Unidos.

La propuesta europea era una extraña mezcla en la que no se sabía bien a qué se le daba importancia y resultaba confusa para aquellos momentos, en los que había zonas del mundo sin Estado en donde imperaba la ley del más fuerte. Era desconcertante porque no se decía cómo extender las bondades cotidianas del continente. No en vano, la ruptura del orden bipolar y la aparición del unipolar habían permitido que aparecieran conflictos que el orden anterior escondía, y eso planteaba graves desafíos al siglo que acababa de comenzar. Porque el tráfico en armas, en drogas o en seres humanos -sin ir más lejos- mostraba claramente tanto la inseguridad mundial como que para vencerlos había que actuar de forma conjunta. Había experiencia suficiente para saber cómo avanzar en esa lucha pero era necesaria una visión menos rígida de la soberanía nacional, un refuerzo de las instituciones multilaterales, o nuevos conceptos de frente bélico, conflicto, frontera o campo de batalla. A simple vista, no parecía sencillo hacerlo.

\section{Y revivieron los paradigmas de la equidistancia...}

¿Qué ocurrió? Que en este mundo inseguro apareció -o reapareció, quizá- como respuesta a los "excesos" de todas las partes -que con frecuencia se simplificaban en dos cosas, el unilateralismo conservador estadounidense y el fundamentalismo islámico- una especie de sensibilidad equidistante que empezó a ganar adeptos, y hubo quien intentó convertirla en paradigma nuevo de las relaciones internacionales en la conocida Alianza de Civilizaciones $(\mathrm{AC}$ ) como fórmula que garantizaba la calidad de la democracia, la estabilidad de las democracias y el respeto a las diferencias de todos los pueblos y de todos los regímenes políticos del mundo.

No toca hablar en esta conferencia de la Alianza, porque ya se hablado y se ha escrito sobradamente de ella, pero sí cabe reflexionar brevemente sobre algo que le atañe y que concierne a lo que estoy contando: $\dot{a}$ sus hermosos postulados, su apacible lirismo, servían para enfrentarse a los problemas del mundo? ¿Era un compendio de intenciones eficaz para frenar a los bárbaros, fuera cual fuera su origen y su color ideológico? ¿Eran -y son- los extremismos exacerbados "de ambos lados" los causantes de los problemas y de la crisis de la democracia y de las democracias -tal y como dice la AC-, o había -y hay- más extremistas en un lado que en el otro? Porque si se quiere lograr equidistancia entre los "radicales" de ambos lados sería necesario que hubiera la misma radicalización en todas las partes, cosa que no es cierta-por ejemplo: ¿̇hay grupos terroristas prooccidentales 
con intención de acabar con todo lo distinto a ellos? ¿Hay Al Qaedas o Hezbolás occidentales? ¿ Hay volúmenes de población parejos, en Occidente y en Oriente, que comulguen con ideas radicales y que amparen la violencia sin límites contra el enemigo?-. Es más: ¿ Es posible plantear como fórmula útil para las dificultades mundiales esta neutralidad de los paradigmas de la equidistancia? ¿ Se puede hablar del poder de la educación para solventar estos problemas, educación cargada de valores ilustrados y, por tanto, etnocéntrica? ¿ Se puede hablar de la igualdad de género, de la globalización de los movimientos juveniles -como repite hasta la saciedad la AC- y al mismo tiempo ser equidistantes? ¿̇Es que en ciertas zonas del mundo cabe siquiera plantearse la igualdad, no ya de género, sino entre los seres humanos? A todo esto se puede responder con un sencillo "no".

No faltan quienes dicen que esta nueva "perspectiva democrática" que no toma partido claro, que se mantiene a la misma distancia de todo, es hermosa, pero ingenua; bella, pero inoperante. Yo diría algo más. Diría que está preñada no sólo de buena voluntad, sino de ideología. En su fondo está el buenismo internacionalista, que se fortalece precisamente en un momento en que el orden internacional requiere fórmulas alejadas por completo de esta tendencia. Y para que ese buenismo prospere, hace falta que se dañe la legitimidad de las democracias liberales, que son, de momento, las únicas que han sido medianamente eficaces para equilibrar libertad, prosperidad, derechos y deberes en el mundo conocido -en el desconocido no se sabe, pero hay experimentos que si salen mal pueden tener pavorosos efectos-. En nuestros días la seguridad de los países -incluso de las civilizaciones, por emplear tan usada terminología- depende de la libertad del resto. Y como un país no puede salvarse a sí mismo en solitario, no es posible quedarse dentro de las propias fronteras, ya sea para protegerse, o tan solo para vivir o sobrevivir, en autarquías prodigiosas. La política, si quiere garantizar la estabilidad del orden internacional, debe basarse en unos pocos principios claros compartidos por la mayoría, sea ésta occidental o no, musulmana o no. El grueso de la gente debe estar convencido de que la democracia tiene virtudes que no tienen otras formas de gobierno. Y esto no se logra con iniciativas baladíes.

\section{La política del apaciguamiento o cómo demoler la demo- cracia liberal}

¿Cómo es posible, entonces, que fórmulas ineficaces gusten tanto, y calen tanto, en las sociedades y en los ciudadanos? ¿Cuál es la explicación? A mi entender se debe a varios principios que voy a desarrollar ahora y que tienen que ver con una 
mentalidad propia del apaciguamiento, más que con la defensa comprometida de la democracia y de los principios morales universales en los que se basa.

1. No son pocos los ciudadanos que están persuadidos de que la paz es un derecho que se consigue por el mero hecho de enunciarlo y de prescindir del empleo de la fuerza. Se suele pensar que la fuerza, por definición, ya sea legal o ilegal, empeora las cosas. Y no me refiero a la violencia, vis injusta según Aristóteles, y a la que se debe despreciar, sino a la fuerza. Es habitual pensar que siempre es mala, grosera e innecesaria; y es cierto que suele serlo. Pero la Historia, desde Tucídides, así como la reciente del siglo XX, que aún marca nuestras vidas cotidianas, enseña lo contrario. Nos dice que el empleo decidido de ella -o a veces la simple amenaza- puede frenar a los tiranos, advertirles de que se está dispuesto a combatirlos, a veces a alto precio. Sin ella -y sin su amenaza- Stalin habría llegado a París, tal y como hicieron los cosacos un siglo antes. Y el Tercer Reich se habría extendido hasta crear un orden internacional nacionalsocialista, tal y como parecía probable a mediados de 1941. En el reciente siglo XX Winston Churchill recordaba con sus palabras y con sus actos que la seguridad, la libertad y la paz dependen de la fuerza de las convicciones, pues cualquier cesión ante un dictador es una invitación a otra exigencia. Recuérdese uno de sus más famosos discursos, pronunciado el 4 de junio de 1940 en la Cámara de los Comunes, cuando la culta y civilizadísima Francia estaba casi derrotada, en el que Churchill decía a sus compatriotas -y al resto del mundo- que debían combatir con creciente confianza y creciente fuerza en las playas, en las colinas, en cualquier lugar, sin rendirse jamás, porque no había más remedio que hacerlo. Y el 18 del mismo mes insistía en que si se flaqueaba en la batalla, el mundo entero se hundiría en el abismo de una nueva era oscura. Es verdad que se refería, de modo tan impetuoso, a la Segunda Guerra Mundial y al nazismo. Pero esa misma reflexión debe mantenerse de forma vehemente en nuestros días si nos referimos a los violentos y a los autoritarios. Ese juicio hay que conservarlo, profese el dictador a quien se combate el credo o la religión que sea. Da igual.

2. De ahí que si la paz es un derecho inalienable obtenido de prescindir de la fuerza, la alternativa a la fuerza sea siempre, y sin restricciones, la negociación y el diálogo -confundiendo, por cierto, estos dos términos, como si fueran sinónimos-. En esta nueva negociación del siglo XXI se prescinde expresamente de la amenaza de la fuerza porque parece poco ética, y se enarbolan principios morales puros. El diálogo es el bálsamo de Fierabrás que sirve para entender al otro, para situarse en su lugar, porque el otro -se diría-, por el hecho de serlo, siempre tiene parte de razón, sea un hombre de paz o un canalla. De esta forma, en permanente diálogo, se puede lograr el acuerdo, el consenso, mediante la cesión de buena fe 
de las partes. Se olvida con este razonamiento que en política, como en la vida, la moralidad pura es narcisista e ineficaz. Y que si la política es el arte de lo posible hace falta dar respuestas morales a las congojas que se le presentan al ciudadano, pero también prácticas, pues de no hacerlo se perjudicará su vida. Mucho más de lo que se suele pensar.

3. Por tanto, este pensamiento de marcado carácter relativista niega la objetividad, la universalidad de ciertos principios y coloca a todos -aunque no se desee- en la senda de la banalidad del mal. Si se hiciera lo anterior, Arendt tendría de nuevo la razón, lo cual sería preocupante porque se estaría repitiendo una corrupción atroz: si no se puede juzgar de manera objetiva porque todo es relativo, se banaliza, por ejemplo, el Holocausto o el crimen. $O$ aún peor: se vuelve relativo lo que le dé la gana a cualquiera, y absoluto lo que le apetezca -por ejemplo: ¿̇el régimen de Irán no hace algo parecido al hablar del Holocausto y, a la vez, de Israel? ¿Acaso no relativiza o niega las maldades de uno, y absolutiza las maldades de otro?- $Y$ se cree, a veces de buena fe, que se puede llegar a acuerdos con quienes violan el orden y los derechos más elementales, como la vida. ¿Se puede llegar a acuerdos con Al Qaeda, Hamás, o Hizbolá? ¿Se puede llegar a acuerdos con quienes creen -póngase acá lo que se quiera: extremistas religiosos de la peor especie, derechistas brutales, fieros izquierdistas- que el único derecho del otro es ser eliminado de la faz de la Tierra? Es difícil hacerlo; peor aún, es imposible. Creer que es posible llegar a acuerdos con regímenes o personajes de este jaez es una versión renovada, y empobrecida a mi entender, de la clásica política de apaciguamiento que abundó en Europa a finales del primer tercio del siglo XX, poco antes del estallido de la Segunda Guerra Mundial, en donde se creía que transigiendo con el monstruo podría satisfacérsele para que dejara en paz a sus potenciales víctimas. $\dot{\partial}^{N} \mathrm{se}$ pensaba en algunas experimentadas cancillerías europeas que si se le entregaban los Sudetes a Hitler, su ambición se colmaría y él se calmaría? ¿ $\mathrm{O}$ que si se aceptaba la ocupación japonesa de Manchuria, el Japón se amansaría? Podemos trasladar esto a nuestros días: si se es comprensivo con los postulados de Al Zawahiri -o con los de cualquier otro fanático semejante- y se soslayan las responsabilidades de la comunidad internacional, se calmará-.

4. Posiblemente todo este entramado se puede orquestar porque, incluso en el mismo Occidente, se desconfía de la democracia liberal. No hablo de duda sana, que es razonable, sino de desconfianza de raíz. La democracia liberal como forma de gobierno suena a derechismo de la peor especie, a anacronismo, a injusticia, a arbitrariedad. Pero es sabido que la suelen detestar quienes rechazan el parlamentarismo y optan por la involución, o por la revolución -que a veces, de facto, coinciden-; es decir, la rechaza desdeñosamente cierta derecha autoritaria y, de 
momento, residual, y cierta izquierda que sigue considerando que la democracia que conocemos es una retorcida emanación del pensamiento burgués. Los fundamentos de la democracia liberal -dicen estos últimos-corresponden a un tiempo histórico pretérito superado por los acontecimientos y por la ideología. Y sugieren, en una especie de ideario marxista resurrecto, que soslayando los principios del Estado demoliberal se alcanzará un tiempo en el que las naciones podrán entenderse en armonía. Se aspira a demoler la democracia liberal, y la propuesta subyacente, o a veces expresa, que es una nueva democracia cuyo contenido y naturaleza se desconoce, carece de solidez teórica y práctica. Es lo que ocurre con el modelo de democracia venezolana, la del socialismo del siglo XXI, en el que el resultado, si se tiene en cuenta lo que afirma esa doctrina y plasma en la constitución política de la república, es un Estado que tiene cinco poderes, y no tres. Alarma este progreso. Por resumirlo: se entiende que la democracia liberal es una experiencia histórica, de facto superada, de la civilización occidental.

5. Es posible que esto enlace con la idea de que la democracia y el capitalismo -ya sea corregido o no, es decir, social y democrático de derecho, o puro y duroson una amenaza. Su triunfo planetario tras la desaparición del imperio soviético ha molestado más de lo que quizá se suponía. Si la globalización ha extendido males, es cierto, pero también las comunicaciones, el comercio y las culturas, hace lo propio con la democracia. $Y$ como ésta se relaciona directamente con el capitalismo, parece que ambos son enemigos de un orden internacional justo - pues a ambos se les achacan, a veces, las culpas de todo lo injusto que ocurre en el mundo-. El combate contra la globalización -no contra sus desmanes o sus errores, sino contra ella entera- es la bandera de todo esto.

6. El relativismo imperante, que niega la objetividad y la universalidad, lleva a decir que los valores se subordinan a las civilizaciones. Es decir, cada sociedad ha de seguir su propia senda y no se pueden juzgar desde fuera de una cultura sus valores. No caben juicios metaculturales, que es algo que decía el marxismo. Por tanto, no se puede juzgar a una dictadura-sobre todo si critica a Occidente, que es responsable directo o subsidiario de casi todo lo malo que ocurre en el mundo-. Es más, si todo es relativo, será relativa la legitimidad de la lucha contra el terror, pues ésta es siempre es una injerencia de carácter etnocéntrico en los asuntos internos de los países. Se dice, por tanto, que la democracia podrá ser distinta en cada lugar y cada sociedad deberá seguir su camino. Sin embargo, esta misma razón resulta perturbadora por la profunda contradicción que encierra, pues si los valores se subordinan a las civilizaciones, ¿̇cómo es posible que se critique de forma objetiva a las democracias liberales? ¿ंNo cumplen acaso con sus valores? ¿ंNo tienen derecho a defender lo que creen, como hacen, por 
ejemplo, los regímenes autoritarios al modo de Castro, las teocracias islámicas o cualesquiera otros regímenes?

7. Por si fuera poco se entiende que la lucha contra el radicalismo en todas sus formas parte de una actitud arrogante y neoimperialista, que es responsable en buena medida de aquél. Es decir, el intento de "imponer" la democracia y los elementos culturales occidentales justifica la respuesta violenta de quienes se ven violentados por estas imposiciones. Cabría pensar, visto esto, si la defensa de los derechos humanos, la división de poderes, la igualdad ante la ley o la igualdad de hombres y mujeres es un pernicioso vicio occidental, o un criterio universal que mejora la convivencia y equilibra los derechos y deberes de las gentes de una forma moderadamente eficaz y justa. Sin embargo, no faltan quienes aseguran que cuando Occidente ceje en su empeño de imponerse al resto del mundo, acabará el radicalismo. Occidente es el agresor. Siempre. Y si esto se cree en ciertos sectores de Occidente "comprensivos" con los radicales y críticos a rabiar con el mundo occidental -que, pese a sus muchos defectos, garantiza sus libertades- los radicales, que conocen las flaquezas occidentales mejor que Occidente mismo, no solo lo creen, sino que se aprovechan de ello en todas sus formas.

Es decir, hay una corriente de pensamiento, o más bien una tendencia, que entiende el mundo de esta forma y que quiere alterar las alianzas, especialmente las trasatlánticas, convencida de que para la causa de la justicia y de la libertad son peores, por ejemplo, los Estados Unidos, con sus rancios convencionalismos y sus tosquedades de toda laya, que los regímenes sometidos estrictamente al cumplimiento de la sharia -por ejemplo- y que lapidan a las adúlteras, o que ahorcan a quienes mantienen relaciones homosexuales, como el iraní. Nótese que no se habla de ciudadanos o de personas -cuya calidad no depende del origen geográfico, ni de la raza, ni de la religión-, sino de regímenes políticos. Impresiona que se produzcan confusiones tan interesadas de ese calibre.

Para esta corriente, para esta tendencia, buena parte de los principios acordados tras varios siglos de convivencia y de defensa de los derechos y de los deberes logrados tras la llustración, deben transformarse. Y su lógica transparente y lineal puede encontrarse en el puñado de razonamientos que diré a continuación: el Estado-nación es conservador $y$, por tanto, se puede disolver y debe hacerse sin complejos. Si, además, como parece comprobarse mal que bien, se avanza en la construcción de la Unión Europea, la Historia pide una transformación del viejo Estado-nación. Añádase que la paz, objetivo supremo, está por encima de todo lo demás y cabe cualquier cosa por lograrla-aunque en el empeño en defenderla se deje avanzar a los bárbaros que aniquilarán a la paz-. Súmese a 
esto, dentro de la lógica relativista, el reconocimiento del derecho de los países a hacer lo que quieran, por tanto pueden mantener regímenes autoritarios sin mediaciones externas -sobre todo si proceden de actos revolucionarios-. Así que cualquier tipo de presión a un régimen que no sea democrático será ilegítimo. En consecuencia, el intento de hacer avanzar la democracia es siempre injerencia y colonialismo de nuevo cuño. Si se permite su avance, habrá más problemas que soluciones, por eso hay que entenderse con los regímenes no democráticos, y no intentar modificarlos. ¿Por qué? Porque se entiende que la globalización -que es liberal-y el orden democrático -fundamentalista, si aspira a ser preeminente en el mundo- son una amenaza para la seguridad más grave, verbigracia, que el terrorismo -que es una respuesta lógica, y quizá legítima, a aquélla-. Así que la globalización y la democracia encienden los ánimos, más que calmarlos.

\section{Breve conclusión}

A mi entender, estos principios están en la base de algunos poéticos pensamientos que critican ardorosamente a la democracia, y creo que buena parte de la gente que los defiende de buena fe es porque desconoce sus efectos -si supiera qué implican, probablemente no lo haría-. Hay tras ello vocación de construir un régimen político pacifista -no pacífico- del siglo XXI, en donde los pueblos convivan en paz e impregnen a las sociedades de entendimiento y colaboración: esto es, regímenes nobles, limpios y amantes de la paz, que enarbolen los más hermosos principios, partidarios del diálogo y que renuncien a la fuerza. No obstante, no se dice cómo se aplica el diálogo allá en donde hay gentes que no quieren dialogar, quizá porque no se sabe cómo hacerlo.

Todas estas hermosas ideas, a las que cualquier ciudadano -también quien les habla- puede adscribirse sin dificultad, insisten en que la paz es el resultado del diálogo. Se diría que si demócratas y no demócratas hablan, si occidentales y musulmanes hablan, si quienes están enemistados, sean cuales sean los motivos, hablan entre sí, tendrán paz. Pero no es verdad, como no lo es la repetida idea que las madres suelen decir en casa para que sus hijos no peleen en la escuela, "dos no riñen si uno no quiere". No es verdad cuando se es niño, y sigue sin serlo de adultos, porque es un principio errado. Si uno quiere reñir de verdad, y otro no, el uno tendrá más probabilidades de éxito. Por si fuera poco, no hay actualmente un problema entre concepciones distintas del mundo que haya que resolver mediante el diálogo. El problema es que unos radicales quieren imponer al resto su visión del mundo por la fuerza y todos somos potenciales víctimas. Hablando entre nosotros 
y con ellos no vamos a frenar al agresor y a obtener la paz. Al contrario, si lo hacemos, perderemos la libertad y la posibilidad de la justicia.

Si en virtud de esta visión del mundo se rechaza expresamente el uso de la fuerza en las relaciones internacionales, si se plantea la disposición a entenderse con cualquier Estado y régimen aplicando las políticas de apaciguamiento, si se reconoce la legitimidad de cualquier gobierno aplicando la idea de que cada sociedad tiene su propio modelo de desarrollo aunque no se respeten los derechos humanos y si se soslaya el viejo principio que pretendía unir a las democracias frente a quienes quieren acabar con las libertades, iremos por mal camino, el de la crisis internacional del sistema político. En realidad, con esta ideología -o con el exceso de buena fe de algunos "supertolerantes" - se le dejará expedito el paso a los violentos. Jamás se le habría ocurrido hacerlo a quienes experimentaron la barbarie de Hitler o de Pol Pot, o a quienes aprendieron de ella. Sin embargo, a comienzos del siglo XXI, los ciudadanos corrientes cuya libertad sobrevive gracias a que otros se enfrentaron y se enfrentan al radicalismo de obra y de pensamiento, lo permiten -lo permitimos, quizá- llevados de la generosa disposición a aceptarlo todo. Como si doblegarse ante el mal volviera mejores a quienes lo hacen y beneficiara a otros hombres.

Delibes, en Un mundo que agoniza, en donde relacionaba la erosión de la naturaleza con la del entorno cultural, decía de soslayo que cuando se degrada el mundo natural, es fácil degradar lo humano que cultivan en él quienes lo habitan. Hay una creación humana, caracterizada por su calmosa nobleza, a la que se humilla sin avergonzarse de hacerlo: la democracia. Y aunque puede dar respuesta a pocas cosas, porque no tiene recetas para solucionar "el problema de la vida" -quizá porque "el problema de la vida" no existe, como decía Wittgenstein, pues hay muchos y distintos problemas, bastantes de ellos sin solución-, sí permite que la existencia humana, cuando es colectiva, transcurra sin excesivos sobresaltos, o con menos confusiones de las que tendrían lugar en otro estado de las cosas. Defenderla no solo es comportamiento propio de caballeros-como decía Borges de las causas perdidas-, sino un acto de rebeldía inconformista, un proyecto moderno que hace más habitable el mundo. Creo firmemente en esto que les digo. Por eso, a mi modesto entender, debemos esforzarnos en mantener activa y vigorosa la sencilla democracia, la serena democracia, aunque solo sea para que el diablo, que es conservador, no gane la partida. 